\title{
Commentary: Differential foregut function based on type of lung disease-Does it really matter?
}

\author{
Mara B. Antonoff, MD
}

\author{
From the University of Texas MD Anderson Cancer Center, Houston, Tex. \\ Disclosures: Author has nothing to disclose with regard to commercial support. \\ Received for publication March 15, 2019; accepted for publication March 15, 2019; available ahead of print April \\ $18,2019$. \\ Address for reprints: Mara B. Antonoff, MD, 1400 Pressler St, Unit 1489, Houston, TX 77030 (E-mail: \\ mbantonoff@mdanderson.org). \\ J Thorac Cardiovasc Surg 2019;158:630-1 \\ $0022-5223 / \$ 36.00$ \\ Copyright (c) 2019 by The American Association for Thoracic Surgery \\ https://doi.org/10.1016/j.jtcvs.2019.03.050
}

Gastroesophageal reflux (GERD) is a frequent issue for patients with end-stage pulmonary disease, ${ }^{1-3}$ and its impact on outcomes for patients undergoing lung transplantation represents an important area of investigation. Among transplant recipients, GERD has been identified as a contributor to bronchiolitis obliterans syndrome and chronic pulmonary allograft dysfunction. ${ }^{4,5}$ The link between benign esophageal disease and end-stage lung failure touches on 2 key areas of clinical relevance for thoracic surgeons, taking the stage as a topic of significant interest in our specialty. ${ }^{6}$ Previous studies have shown that fundoplication slows the decline of lung function in transplant recipients with GERD, and that early intervention appears to be protective in avoiding reflux-induced injury. ${ }^{7}$

While patients with both obstructive and restrictive lung disease have been shown to have abnormal foregut function, differences in the specific types of esophageal disorders between these groups exist. ${ }^{8}$ Understanding the typical course of esophageal dysfunction for patients before and after lung transplant according to the nature of their lung disease may be particularly helpful in rendering decisions regarding when to offer esophageal intervention. In this issue of the Journal, Masuda and colleagues ${ }^{9}$ have built upon their previous work, aiming to evaluate the effect of lung transplantation on foregut function according to the underlying disease type.

In this well-written retrospective review, Masuda and colleagues ${ }^{9}$ describe results of foregut function testing before and after transplant, specifically comparing differences between individuals with restrictive versus obstructive lung disease. They found that pretransplant GERD was more than twice as prevalent in patients with restrictive disease (43\% vs $20 \%$ in obstructive disease), which they attributed to a significantly greater thoracoabdominal pressure gradient in this group. As a result of improvements in respiratory mechanics and increased esophageal peristaltic vigor, patients in both groups showed changes in posttransplant manometry findings. Among all patients in the study,

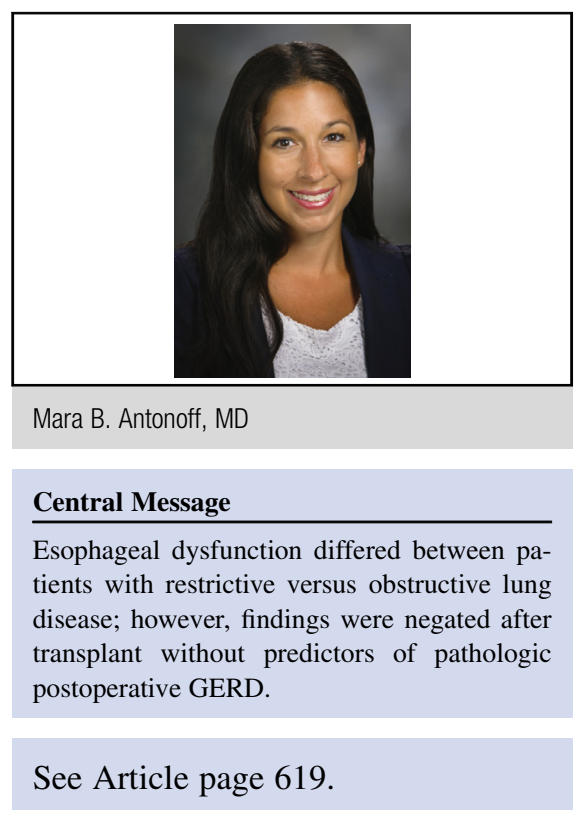

approximately half of patients with pretransplant reflux no longer had GERD after the transplant. However, about a quarter of patients without preoperative GERD developed it after transplantation. Thus, the overall prevalence of pathologic reflux did not change significantly in the overall study population. ${ }^{9}$ Given the difficulty in predicting postlung transplant reflux, Masuda and colleagues ${ }^{9}$ have suggested that fundoplication should be considered after transplantation and repeat foregut function studies.

This study has expertly built on a growing body of evidence in this area, adding to the existing literature produced by this team of authors. Through this recent work, greater understanding has been achieved in clarifying abnormalities in esophageal function correlated with specific pulmonary diagnoses. However, there are some key limitations that ought to be recognized. Nearly a third of patients who underwent lung transplant during the study period were excluded because of incomplete foregut function testing, related to emergency transplantation or critical illness posteroperatively. While this rationale for exclusion is completely understandable, we must also recognize that individuals who are quite ill perioperatively are also those patients for whom we are most eager to find means of improving outcomes and postoperative lung function. Moreover, given that the primary differences between patients with restrictive and obstructive lung disease were negated posttransplant, and Masuda and colleagues ${ }^{9}$ 
recommend esophageal intervention only for those recipients with postoperative pathologic GERD, it is not clear that the differences between the groups are of any interveneable clinical relevance.

Despite the fact that the differences demonstrated between the groups do not persist postoperatively, this study still provides some key take-home points. Recognizing that a substantial number of patients' esophageal function changes from pre- to posttransplant, esophageal function testing should habitually be repeated postoperatively. Taken with the authors' previous work, it is clear that, after transplantation, assessment for modifiable reflux and early fundoplication when indicated provide the potential to delay decline in lung function. ${ }^{7,9}$ Furthermore, additional studies are clearly needed to determine before transplant which patients would best be served by esophageal intervention.

\section{References}

1. Davis CS, Shankaran V, Kovacs EJ, Gagermeier J, Dilling D, Alex CG, et al. Gastroesophageal reflux disease after lung transplantation: pathophysiology and implications for treatment. Surgery. 2010;148:737-44; discussion 744-5.
2. D’Ovidio F, Singer LG, Hadjiliadis D, Pierre A, Waddell TK, de Perrot M, et al Prevalence of gastroesophageal reflux in end-stage lung disease candidates for lung transplant. Ann Thorac Surg. 2005;80:1254-60.

3. Masuda T, Mittal SK, Kovacs B, Smith M, Walia R, Huang J, et al. Thoracoabdominal pressure gradient and gastroesophageal reflux: insights from lung transplant candidates. Dis Esophagus. 2018;31:doy025.

4. Griffin SM, Robertson AG, Bredenoord AJ, Brownlee IA, Stovold R, Brodlie M et al. Aspiration and allograft injury secondary to gastroesophageal reflux occur in the immediate post-lung transplantation period (prospective clinical trial). Ann Surg. 2013;258:705-11; discussion 711-2.

5. Weigt SS, Wallace WD, Derhovanessian A, Saggar R, Saggar R, Lynch JP, et al Chronic allograft rejection: epidemiology, diagnosis, pathogenesis, and treatment. Semin Respir Crit Care Med. 2010;31:189-207.

6. Antonoff MB. How much does early fundoplication for lung transplant recipient with gastroesophageal reflux disease truly help? Challenges in escaping the perils of retrospective review. J Thorac Cardiovasc Surg. 2018;155:2772-3.

7. Biswas Roy S, Elnahas S, Serrone R, Haworth C, Olson MT, Kang P, et al. Early fundoplication is associated with slower decline in lung function after lung transplantation in patients with gastroesophageal reflux disease. J Thorac Cardiovasc Surg. 2018;155:2762-71.e1.

8. Seccombe J, Mirza F, Hachem R, Gyawali CP. Esophageal motor disease and reflux patterns in patients with advanced pulmonary disease undergoing lung transplant evaluation. Neurogastroenterol Motil. 2013;25:657-63.

9. Masuda T, Mittal SK, Kovács B, Smith MA, Walia R, Huang JL, Bremner R M. Foregut function before and after lung transplant. J Thorac Cardiovasc Surg. 2019;158:619-29. 